\title{
Bipolar Obligations, Recognition Respect, and Second-Personal Morality
}

\author{
Jonas Vandieken ${ }^{1,2}$ (D)
}

Received: 24 August 2018 / Accepted: 11 June 2019 / Published online: 29 June 2019

(C) The Author(s) 2019

\begin{abstract}
Any complete theory of "what we owe to each other" must be able to adequately accommodate directed or bipolar obligations, that is, those obligations that are owed to a particular individual and in virtue of which another individual stands to be wronged. Bipolar obligations receive their moral importance from their intimate connection to a particular form of recognition respect that we owe to each other: respect of another as a source of valid claims to whom in particular we owe certain treatment and, at the very least, an apology if we fail to accord that treatment. While some of the most prominent accounts of interpersonal morality fail to adequately accommodate bipolar obligations, I here investigate a recent proposal that explicitly seeks to improve on these accounts-Stephen Darwall's second-personal theory of morality. Ultimately, I object to Darwall's theory on the grounds that his secondpersonal theory normatively ties bipolar obligations too closely to non-directed moral obligations or those that we are under, period. The problem for Darwall's account is that any obligations that at first appear to be bipolar and owed to someone in particular turn out to be instances of non-directed moral obligations period that have their normative source in the representative authority of the moral community. Adequately accommodating bipolar obligations requires taking seriously a novel second-personal approach, according to which we locate the normative sources of our interpersonal obligations in the claims and demands particular persons and deliberate from what I call the pairwise or bipolar standpoint.
\end{abstract}

Keywords Bipolar obligation · Second-person standpoint · Recognition respect · Attitudinal wronging $\cdot$ Individual authority $\cdot$ Apology

Jonas Vandieken

jonas.vandieken.13@ucl.ac.uk

1 Ludwig-Maximilians-University Munich, Schellingstr. 10, 80799 Munich, Germany

2 University College London, London, UK 
Certain obligations are owed to particular others. When my friend Jane is in the hospital I owe it to her to visit. That is, I don't owe it to just anyone to visit Jane. What is more, I would not only do something wrong in failing to show up at the hospital, I would thereby wrong Jane. Thus, we might say, my obligation is one that I owe to Jane. Similarly, we tend to think that there are certain actions and obligations that we owe to particular others simply qua being our moral fellows. When I step on your foot on the train to place my luggage in the overhead locker more conveniently I wrong you, I don't just do something wrong. And in turn, we might think that I have an obligation to you not to step on your foot.

Both of these obligations - the obligation I have to visit my friend at the hospital and the obligation not to step on your foot-fall under the class of directed or bipolar obligations, obligations that involve "two poles:" a person who is under the relevant obligation (obligor) and a person to whom the obligation is owed (obligee). ${ }^{1}$ Bipolar obligations have their source in the legitimate claims and demands of the person to whom they are owed-they are constitutively connected with another person's claim ${ }^{2}$ - and are linked to a particular conception of recognition respect: in acting from a bipolar obligation that one is said to owe to another, one recognizes and acknowledges the other as a separate "self-originating source of valid claims". Accordingly, I take bipolar obligations to be most adequately captured not only as obligations that we have to another, but as obligations that we have because of another. One more clarification to avoid possible confusion: The claims and demands correlating with bipolar obligations as actual claims need not have to be addressed to another person in order to generate an obligation. That is, having a claim need not require the action or activity of making or pressing that claim. Quite to the contrary, the relevant claims and demands are to be understood as generating bipolar obligations independently of the activity of addressing or making. After all, it would be implausible to believe that I'm under an obligation to you not to step on your foot only after you have actually addressed the relevant demand to me. ${ }^{3} \mathrm{My}$ bipolar obligation to you not to step on your foot does not correlate with a claim

\footnotetext{
1 Thompson (2004) and Darwall (2013a). For the rest of the paper, I will speak of bipolar-, rather than directed-, obligations.

2 This is what we can call Hohfeld's thesis (Hohfeld 1923), or, as others sometimes call it, the thesis of correlatity (e.g. Hart 1955; Weinrib 1995; Thompson 2004; May 2015). The thesis explains how the obligee's claim or claim-right carries direct normative import for the obligation of another and thus distinguishes the obligee's claim from the concerns or interests of any uninvolved third party. Consider the following case: I promised to Jane to look after Stan. The thesis of correlativity explains how upon breaking my promise, I do not wrong Stan, but Jane. For, while Stan might have had an interest in, and benefit from, me looking after him, he did not have any claim against me-Stan merely figures in the content, and hence as the occasion, of an obligation owed to Jane. Some also speak of the 'constitutive connection' that holds between one's obligation and another person's claim. One reason for invoking the notion of constitutive connection might be that speaking of correlativity does leave some room for not fully capturing what is supposed to be captured. After all, what we want to capture is the thought that one has an obligation not only to, but because of another. On a weaker reading of correlativity, the 'because $o f$ ' is not yet entailed by the relation of correlativity between one's claim and another's obligation. I take it however, that the thesis of correlativity is supposed to capture the stronger reading, according to which the 'because of' is always already entailed. Some call this 'tight correlativity' (Lyons 1970: 46).

3 See also, May (2015) and Wallace (2007).
} 
that you actually make but with a claim in virtue of which you have the standing to make the relevant demand of me. Bipolar obligations contrast with non-directed or monopolar obligations that involve only one "pole:" a person who is under the relevant obligation, simpliciter or period. While one can have non-directed obligations to do or refrain from doing certain things concerning another person, these obligations are never owed to anyone in particular, but are merely had with regards to another person. ${ }^{4}$ Violating a non-directed obligation does hence not amount to wronging anyone in particular, but to a wrong simpliciter.

The aim of the paper is to argue that any adequate theory of "what we owe to each other" must be able to adequately accommodate bipolar obligations to and recognition respect of others as sources of valid claims (Sect. 1) and to investigate the most sophisticated recent proposal that explicitly seeks to do just that-Stephen Darwall's secondpersonal theory of morality (Sect. 2). While Darwall's theory at first glance appears to be readily able to adequately accommodate bipolar obligations to and recognition respect of another as a source of valid claims, I ultimately raise the following objection to his second-personal account (Sect. 3): in tying bipolar obligations too closely to non-directed "moral obligations, period," Darwall's second-personal proposal fails to account for the kind of recognition respect that we are said to owe to others as "selforiginating sources of valid claims." More specifically, I argue that Darwall ultimately locates the source of all of our moral obligations, including our bipolar obligations, in the representative authority of the moral community and not in the individual authority of a particular person. I consider two possible replies on behalf of Darwall that I ultimately take to be unsuccessful in doing away with the objection. While the central aim of the paper is to critically engage with and ultimately reject Darwall's secondpersonal account of bipolar obligations, I close by (Sect. 4) suggesting that adequately accommodating bipolar obligations and bipolar recognition respect requires taking seriously a novel second-personal approach to interpersonal morality, according to which we locate the normative sources of our obligations that we owe to each other exclusively in the individual authority of a particular person and deliberate from the bipolar standpoint. In doing so, the paper aims to pave the way for the search for a novel relational account of the morality of "what we owe to each other," one that is more robustly second-personal than Darwall's own account.

\section{Attitudinal Wronging, Recognition Respect, and Bipolar Obligations}

Why should we care about whether someone has a bipolar obligation to you, rather than a non-directed obligation with regard to you? I shall here take up this question and suggest that an important part of what we owe to each other consists in

\footnotetext{
${ }^{4}$ Hence, some might think that we have a non-directed obligation to give to charity, to bring about the best overall state of affairs, or to respect humanity as such. These obligations do not have their source in the claims of particular individuals, but in some non-directed norm, as a result of which persons simply figure as the occasion or content of the relevant obligation that one has with regard to them.
} 
recognizing each other as sources of valid claims, failure of which amounts to a particular kind of moral wrong.

To begin with, consider an obligation that one has to not fell a revered city tree. ${ }^{5}$ There seems nothing wrong in conceiving of the obligation not to fell the tree as merely a non-directed or monopolar obligation that one has with regard to the tree. As such, it seems perfectly fine for someone to register the tree in one's practical deliberation simply as the target or "occasion" of a monopolar obligation that we have with regard to it and in virtue of which we might do something wrong, simpliciter or period. ${ }^{6}$ To put this in the memorable language of Michael Thompson, trees are "raw material in respect of which one might do wrong" (Thompson 2004: 344).

Next, consider an obligation that one has to a person. In contrast to the city tree, a person is, to again invoke Thompson's language, a "wrongable" being (Thompson 2004: 368). While trees and other natural artifacts certainly count in their own right and hence provide us with strong reasons against doing certain things with regard to them, e.g. fell a particular city tree, the kind of constraint that these objects put on us is surely different from the constraints that the moral status of a person puts on us. Something goes amiss when I conceive of you or Jane in exactly the same way that I conceive of a tree-simply as the target or "occasion" of a non-directed obligation that I have with regard to each of you. Accordingly, we normally speak of someone being the victim of one's wrongdoings, not simply the target or "occasion" of one's moral fall (Thompson 2004: 340). ${ }^{7}$

\subsection{Attitudinal Wronging and the Target-Source Distinction}

If we grant the above and assume that in failing to do what I owe to you and Jane, I wrong each of you, we can capture the difference between the tree and you or Jane as follows: you are not merely the target or "occasion" of my obligation, but always also its source. In presupposing that I wrong you as the victim of my foot-stepping, we in fact presuppose that those obligations that we owe to other persons and in virtue of which they can be wronged are directed or bipolar and therefore correlative to the valid claims of the individual to whom they are owed. Hence, that I wrong you, but not the tree, is explained by the fact that you have a claim against me that I not step on your foot. And it is precisely in virtue of possessing such a claim against me that you figure as the respective source of my obligation not to step on your foot. It is, as we might say, because of your valid claim that I'm obligated not to step on your foot and at risk of wronging you in case I actually do so.

\footnotetext{
5 This implies that the city tree is not the bearer of a moral claim against anyone.

6 This is not to say, however, that there is no way in which we can speak of the relevant obligation as being owed 'to' the tree; after all, the tree stands as the target or occasion of the obligation not to fell it and the obligation is in this sense ' $t o$ ' the tree. But this sense of ' $t o$ ' is very different from the sense in which we speak of my obligation as being owed 'to' you, insofar as the latter, but not the former, is constitutively connected with, and has its normative source in, a valid claim against me.

7 In other words, I do not only "violate a binding norm," but violate "another person" in failing to do what I owe to them. See Lavin (2014: 284).
} 
You and Jane are "self-originating sources of valid claims" who, unlike the tree, freely and autonomously traverse the moral universe, possess the standing to demand certain conduct of others, hold them to account or conversely, and give consent to their doing what would otherwise be forbidden. In turn, each of you has an interest in being recognized as such a source and is prone to a "distinct kind of vulnerability, a vulnerability to what another's reasons, or reasoning, concerning how it is appropriate to relate to oneself, says about oneself" (Kumar 2003: 107). Does another relate to oneself only as the target of a non-directed obligation that he or she has with regard to oneself or does the other recognize one as the source of a directed or bipolar obligation that another has to and because of oneself? And it is precisely this kind of relational vulnerability that opens up a person to be wronged by another. Rahul Kumar puts this point as follows:

"For though one may have not made the other worse-off, the way in which one has related to the other may still express a failure to have appropriately recognized and taken account of a person's value as capable of rational self-governance. A person can be wronged, then, simply in virtue of how she figures, or does not figure, in how one is rationally disposed to relate to her" (Kumar 2003: 109).

This need not mean that any failure to recognize a person properly is necessarily a failure to recognize her capacity for self-governance. Instead, and slightly deviating from Kumar here, we can understand this as possibly including a failure to recognize a particular person's claims and demands. It is in virtue of this vulnerability that we can be wronged in a distinctly attitudinal manner without being necessarily harmed or injured, by being overlooked, disregarded or neglected. This can manifest itself in the experience of being physically present, but morally walled out, an experience that Philippa Foot describes as a distinctively "second-order evil" of human life (Foot 1994).

Applied to the obligations that I have to you or Jane, this might play out as follows: suppose I fail to comply with the respective obligations that I have to Jane and you. In that case, it seems as though I would be missing something crucial were I just to admit to the world that I did something wrong simpliciter. After all, what both Jane and you would expect is an apology to each of you respectively, and hence my acknowledgement of having wronged Jane and you in particular by disregarding each of your valid claims and demands of me. In failing to realize that, I would wrong you and Jane precisely in regarding both of you merely as the target or "occasion" of my monopolar obligation - the "raw material in respect of which one might do wrong" (Thompson 2004: 344) — and hence in disregarding the person that is you or Jane and each of your particular claims as the source of my respective obligation.

Therefore, even in doing 'the right thing', I can wrong you. How so? By acting from the wrong kind of reasons and failing to make you the proper object of my moral concern. After all, I might do what I'm obligated to do, but might conceive of my obligation as non-directed or one that I have simpliciter and to no one in particular, and not as one that I have specifically to, and because of, another. I could simply show up at Jane's bedside because I thought it was my duty to do so, or because my 
brother told me to do so, and not because of my friendship with Jane. ${ }^{8}$ Similarly, I could refrain from stepping on your foot, but do so simply because I lost interest in doing so or do so only because I care about fulfilling my non-directed moral duty. As a result, I would in one case be a bad friend, failing to exhibit the kind of particularizing love or concern characteristic of friendship, while in the other I would be a disaffected moral fellow (and possibly a moral fetishist) ${ }^{9}$ who cares only about doing whatever is either most conducive to one's own interest or to the fulfillment and compliance of certain moral rules or principles. I would, in other words, fail to properly recognize each of you.

\subsection{The Principle of Bipolar Recognition Respect}

An important part of what we owe to our friends as well as to our moral fellows is that we recognize one another not only as the targets but also the sources of those obligations that owe to them, or as the very reason for which we are under the relevant obligation. What is called for in both cases is bipolar recognition respect, that is, respect for the other as ' $y o u$ ' and not merely as the target of a ' $t o$ ', so to speak:

Bipolar Recognition Respect A respects B only if A recognizes B not only as (1) the target of A's obligation owed to B, but also as (2) the source of the obligation that A owes to B.

1. For A to recognize B as the target of A's obligation to $\varphi$, A ought to recognize $\mathrm{B}$ as the person to whom $\mathrm{A}$ has the obligation to $\varphi$.

2. For A to recognize B as the source of A's obligation to $\varphi$, A ought to recognize B and her particular claim as the reason for which A ought to $\varphi$.

While (1) states a (minimal) normative condition of respect-other things being equal, to respect another is to identify and do the right thing to the other in a given situation-(2) states a motivational condition of respect-to respect another is to be motivated to do the right thing for the right kind of reason, where the latter is understood in terms of the relevant claims and demands that the person to whom the obligation is owed is in a position to make of another.

Importantly, bipolar recognition respect, as respect more generally, is a forwardlooking attitude. It calls for ex ante recognition of the other, that is, recognition of the other and his or her valid claims and demands as the normative source of one's obligation that has yet to be undertaken, and not only for ex post recognition, that is, as someone to whom one is accountable and whose complaints one must respond

\footnotetext{
${ }^{8}$ For an excellent discussion of the problematic nature of my motives in this scenario, see also Stocker's influential discussion on the 'schizophrenia in modern moral philosophy'. Stocker (1976).

9 For a related criticism of moral fetishism, see Michael Smith's interesting discussion about de re and de dicto desires in 'The Moral Problem' (1994), which resembles in important respects the distinction I have tried to draw here between acting merely for the sake of doing the right thing and acting for the sake of, say, another person as one's friend.
} 
to after an obligation has been violated. ${ }^{10}$ That is, I properly respect you only if I recognize you and your ex ante claim that you have the standing to press against me as the normative source of, and thereby settling the fact of, my obligation not to step on your foot. So understood, bipolar recognition respect places a constraint on the kinds of reasons that can figure in our deliberation when faced with the question concerning what we owe to one another. Put more plainly, bipolar recognition respect generates a special kind of reason for action-a claim-based reason. What it is for a reason to be claim-based is for that reason to have its source in the claim of a particular individual and for it to settle the fact of an obligation yet to be undertaken to do $\varphi$ to another person. According to the principle of bipolar recognition respect, one does 'the right thing' to another for the right kind of reason in acting from a claim-based reason.

What the previous discussion seeks to illustrate is that bipolar obligations to another and bipolar recognition respect, that is, recognition respect or acknowledgement of another as a source of valid claims, are intimately connected. ${ }^{11}$ To have a bipolar obligation to another and to act accordingly involves recognizing and acknowledging the other as the normative source of, or the very reason for which one is under, the relevant obligation; the obligation "characterizes what it means to respect you." 12 For, what underlies bipolar obligations are the valid claims of the particular individuals to whom these obligations are owed. Conversely put, then, to respect another as a person, a "self-originating source of valid claims," one must do what one is said to owe another not only to, but because of, the other. Bipolar obligations, as we might now say, are, importantly, recognizing obligations.

\subsection{What We Owe to Each Other}

Any adequate theory of "what we owe to each other" that seeks to account for bipolar recognition respect must be able to adequately accommodate bipolar obligations. As such, any theory that operates exclusively with non-directed or monopolar obligations will be eliminated from contention for offering us such an adequate theory of "what we owe to each other." Take, for example, an indirect rule-consequentialist theory of morality, according to which one ought to follow the rules and practices that are most conducive to the best overall state of affairs (e.g. Brandt 1959; Hooker 2000). While such a theory will certainly incorporate obligations with regard to other individuals, these obligations are ultimately non-directed or monopolar obligations to bring about the best state of affairs and hence obligations simpliciter owed to no one in particular. Accordingly, rule-consequentialism cannot make sense of

\footnotetext{
10 See also Cornell (2015) on the difference between ex ante and ex post recognition. The perspective of respect, as a form of ex ante recognition, "considers how one should be guided in an action that has yet to be undertaken. Looking forward, respect for a person's status may demand giving him or her special significance in one's deliberation." Cornell (2015: 139).

11 We might in fact call this Feinberg's claim, for according to Feinberg "to respect a person then, or to think of him as possessed of human dignity, simply is to think of him as a potential maker of claims." Feinberg (1970: 8).

12 Cornell (2015: 138).
} 
the idea that certain obligations are owed to, and incurred because of, a particular individual that stands to be wronged by the relevant action. To be clear, this is not to say that consequentialists of this kind cannot make sense of the idea that the fate of particular individuals has a bearing on the best state of affairs.

It even seems that indirect rule-consequentialism has, at first glance, room to incorporate the phenomenon of bipolar obligation and its associated form of recognition respect. For, even the rule-consequentialist will hold that when I'm under an obligation to keep my promise to you, it matters that I do what I promised to you, for any harm that I might inflict on you by breaking my promise without adequate excuse would have a significant effect on the overall state of affairs. In turn, this seems to imply that keeping my promise to you would contribute significantly to the overall state of affairs - that complying with my bipolar obligation to you matters. ${ }^{13}$ But that you would be harmed by my failure to keep my promise, or, conversely, that keeping my promise to you would contribute to the overall state of affairs- that you are implied in, and affected by, my action as its content-should not be confused with the idea that I genuinely owe it to you to keep my promise. For, ultimately, you are simply the "occasion" or target of a monopolar obligation that I have with regard to, and never because of, you to do what brings about the best state of affairs. After all, the relevant obligation does not correlate with any of your valid claims against me to keep my promise to you. Quite to the contrary, I'm under the relevant obligation only insofar as complying with it upholds a socially useful practice or rule that contributes to the best state of affairs. Any seemingly bipolar obligation consequently reduces to, insofar as it receives its normative import from, a monopolar obligation that is not owed to anyone in particular. While rule-consequentialism can hence very well explain the wrongness of breaking my promise simpliciter, it cannot explain why it wrongs you. ${ }^{14}$

Even some of the most prominent deontological theories that explicitly seek to capture "what we owe to each other" and its associated forms of recognition respect fail to provide us with an adequate theory of that part of morality. T.M. Scanlon's moral contractualism by the same name locates the normative source of the entire set of interpersonal obligations ultimately not in the valid claims of particular individuals but in general moral principles that no one could reasonably reject (Scanlon 1998). According to Scanlon, " $[\mathrm{a}[\mathrm{n}$ act is wrong if its performance under the circumstances would be disallowed by any set of principles for the general regulation of behavior that no one could reasonably reject as a basis for informed, unforced, general agreement" (Scanlon 1998: 153). This contractualist principle functions like

\footnotetext{
13 As such, rule consequentialism might very well incorporate bipolar-obligation-generating practices, like promising, if they are deemed socially useful. See also Darwall (2013a, b: 24-25).

14 I take it that the same worry that besets rule-consequentialism will ultimately also beset versions of act-consequentialism, given that act-consequentialists, too, will operate solely with monopolar obligations or those that we have simpliciter. Might there be other variants of consequentialism that can possibly account for genuine bipolar obligations? While I'm ultimately skeptical, there might be versions of "sophisticated consequentialism," such as the one defended by Peter Railton (1984), that are able to do so. I won't be able to settle this question here, but am grateful to an anonymous reviewer for pointing this possibility out to me.
} 
a monadic rule or law and determines, as stated, whether or not any acts are wrong simpliciter and not whether any acts constitute wrongings of other individuals in particular. Claims of particular individuals do not figure on Scanlon's account as input into our moral deliberation about what we owe to each other. Quite to the contrary, we deliberate about what we owe to each other solely on the basis of general moral principles, which are "principles of wrongness, not of wronging" (Wenar 2013: 385).

In grounding interpersonal obligations in general moral principles void of genuine Hohfeldian correlativity, Scanlon's moral contractualism renders it similarly mysterious how one can be obligated to and because of another and how a person stands to be wronged by someone's actions. This is true despite Scanlon's insistence that his moral contractualism improves upon consequentialist and in particular practice-based accounts of promising in being able to explain how someone's promise is always "owed to a specific individual" (Scanlon 1998: 316). For on Scanlon's contractualist account, the obligation to keep my promise to you is ultimately not explained by your correlative claim against me, but by Principle F, yet another general moral principle, violation of which amounts to a wrong simpliciter. ${ }^{15}$ As such, any seemingly bipolar obligation to you ultimately reduces to an instance of a nondirected or monopolar obligation simpliciter that I've incurred because of Principle F and is as such owed to no one in particular (Gilbert 2004; Darwall 2013b; Wenar 2013).

The shortcoming of both the rule-consequentialist and contractualist view is that these views merely give you the normative standing as the "occasion" or target of a non-directed or monopolar obligation that I have with regard to you and in virtue of which I can do wrong simpliciter, but can never wrong you in particular. ${ }^{16}$ Given that the reason underlying my obligation is on these views never claim-based, but always only norm- or principle-based, I cannot afford you the kind of bipolar recognition respect that I owe to you. As a result, I act towards you for the wrong kind of reasons.

If we want to adequately explain and account for bipolar recognition respect, we need a theory of "what we owe to each other" that can adequately explain and account

\footnotetext{
15 Principle F: "If (1) $A$ voluntarily and intentionally leads $B$ to expect that $A$ will do $X$ (unless $B$ consents to $A$ 's not doing so...then, in the absence of special justification, $A$ must do $X$ unless $B$ consents to $X$ 's not being done)." All that Principle F states is that a promisor must under certain conditions keep her promise. Nothing in Principle F states that the promisor is under a bipolar obligation to and because of the promisee's correlating claim.

16 This is the sort of 'occasionalism' that Feinberg (1970) invokes as part of his discussion of the fictional society of 'Nowheresville', a society that has all the relevant moral furniture except for claimrights, in order to illustrate the shortcomings of both consequentialist and deontological views. What we can do in Nowheresville is to distinguish between right and wrong simpliciter, good and bad. The only normative game in town is that of monadic normativity, with its associated obligations being nondirected ones owed to no one in particular. While we can harm others in Nowheresville, we can never wrong them. As a result, no one is ever properly respected in Nowheresville, because genuine respect for persons, according to Feinberg, requires one to recognize the other not merely as the occasion of a monopolar obligation but as possessing the standing to make claim-based demands and to function as the normative source of an obligation.
} 
for bipolar obligations without reducing to monopolar obligations and associated forms of target- or "occasion"-respect. One might in fact think that we need a normative reversal: from monopolar to bipolar. According to the resulting view, we would understand the entire set of obligations that we can be said to owe to each other itself in terms of bipolar obligations that have their normative source in the valid claims of particular individuals. Seemingly non-directed or monopolar obligations would simply reduce to bipolar obligations. Deliberating from the bipolar standpoint, we would no longer run the risk of misrecognizing others as mere targets or occasions, for we would always recognize them as the sources of bipolar obligations that we owe to them and as such as possessing bipolar standing. Recently, the project of understanding the morality of "what we owe to each other" in these fundamentally bipolar terms has gained some traction in the literature (e.g. Wallace 2019; Zylberman 2017). This represents a potentially radical shift in moral theorizing and many remain skeptical of such a complete normative reversal (e.g. Kamm 2007; O’Neill 1989; Raz 1986; Sreenivasan 2010).

For, how plausible is it to understand all interpersonal obligations in fundamentally bipolar terms? While there are certainly many obligations that are genuinely bipolar and need to be captured as such, many believe that a number of obligations that "we owe to each other" appear to be best captured as simply non-directed or monopolar obligations simpliciter. Take, for example, the obligation to separate my trash. While it's plausible to think that I owe this to my fellow citizens, no one individual in particular seems to have a claim against me that I do so. That is, while I might owe it to, I might not be under the relevant obligation because of, you. After all, who are you to tell me that I ought to separate my trash? Quite to the contrary, I might simply have the relevant obligation with regard to you. ${ }^{17}$ What we need, it appears, is not a complete normative reversal of the sort envisioned by proponents of a bipolar standpoint. Instead, many theorists believe that we simply need to make room for a genuine "realm of rights" within the wider continent of morality (Thomson 1990: 3) —a theory of "what we owe to each other" that clearly separates genuinely normative bipolar obligations from monopolar obligations.

\section{Darwall on Bipolar Obligation and Recognition Respect}

A theory that attempts to provide such a clear normative separation and improve upon the fundamentally monopolar or monadic model of both the rule-consequentialist and the contractualist is Stephen Darwall's second-personal theory, according to which the authorities to which our moral consciousness appeals are simply you and I. ${ }^{18}$ More specifically, the relevant moral standpoint is on Darwall's view best described as second-personal or "the perspective you and I take up when we

\footnotetext{
17 See, for example, Scanlon (2013: 405): "It would be wrong not to do these things, but it does not seem to me that other citizens have a right that we do them, or that I wrong anyone in particular by failing [to do them]."

18 As a matter of fact, Darwall explicitly argues that his theory is better equipped to properly account for the directed or bipolar nature of a certain class of obligations - promissory obligations - than the ruleconsequentialist theory or Scanlon's principle-based contractualism. Darwall (2013b: 131-154).
} 
make and acknowledge claims on one another's conduct and will" (Darwall 2006: 3 ). Accordingly, for me to be obligated to $\varphi$ means for you to be justified in holding me accountable by demanding that I $\varphi$ and blame me in case I fail to $\varphi$ without adequate excuse. Moral reasons are on Darwall's account inherently demand-regarding and claim-based.

\subsection{Authority and Recognition Respect}

Understanding moral reasons to be inherently demand-regarding and claim-based allows Darwall to provide us with a distinctive second-personal conception of moral recognition respect, according to which the proper object of our ethical concern is always the second-personal authority, standing, or dignity ${ }^{19}$ of a person:

"The dignity of persons, I contend, is the second-personal authority of an equal: the standing to make claims and demands of one another as equal free and rational agents, including as a member of a community of mutually accountable equals" (Darwall 2006: 121)

Importantly for Darwall, the very recognition of this second-personal authority is itself second-personal. That is, in order to respect others as our moral equals, it does not suffice to simply recognize a fact about or quality in them. Instead, one must relate to and express a certain attitude towards them. ${ }^{20}$ Consequently, we ought not only recognize the other's second-personal "standing to demand, remonstrate, resist, charge, blame, resent, feel indignant, excuse, forgive, and so on" but also secondpersonally acknowledge this very authority by making ourselves accountable to them (Darwall 2006: 141).

On Darwall's view then, one has to treat others not only in the right way by doing 'the right thing', but moreover, one must do what one is obligated to do because others have the authority to demand the relevant action of one, and hence acknowledge others as the normative source of one's obligation:

"Someone might accept the first-order norms that structure the dignity of persons and regulate himself scrupulously by them without yet accepting anyone's authority to demand that he do so. He might even accept these as mandatory norms without accepting any claim to his compliance. I hope it is now clear that although such a person would thereby respect the duties with which persons can demand compliance, in failing to respect their authority to demand this, he would also fail, in an important sense, to respect them. He would fail to acknowledge their equal authority as free and rational and so fail to relate to them on terms of equal respect" (Darwall 2006: 140)

\footnotetext{
19 These concepts can be used interchangeably. I will mostly refer to authority from here on out.

20 Second-personal authority "can only be adequately recognized second personally, through relating to others in a way that acknowledges their second-personal authority... When others 'look us in the eye' and claim their rights against us, we recognize their second-personal authority by looking back at them with acknowledgment" (Darwall 2013b: 195).
} 
Importantly, Darwall distinguishes between two kinds of standing or demand-making authority that we possess and in virtue of which we can hold others accountable. On the one hand, as members of the moral community we possess a shared representative authority to make moral demands and hold each other accountable via the so-called impersonal reactive attitudes, like blame and indignation (Darwall 2013a: 27). ${ }^{21}$ Any demands that we have the representative authority to make are non-discretionary and its resulting obligations are non-directed or monopolar ones we have "period" and to no one in particular (Darwall 2013b: 32).

On the other hand, each person possesses the individual authority to make demands of others and hold others accountable via the so-called personal reactive attitudes, like resentment. This individual authority involves the standing to make discretionary demands that generate bipolar moral obligations that we owe to others in particular. Thus, you possess the individual authority to demand of me not to step on your foot. I owe it specifically to you not to do so, and you have the authority to hold me personally accountable in case I fail to comply with said obligation, an authority that others lack (Darwall 2006: 27, 2013a: 31-32). It is through the notion of individual authority to make demands of others that, according to Darwall, we express the idea that persons are "self-originating source of valid claims" (Darwall 2006: 121).

With this distinction between representative authority and individual authority in mind, we get the following view of second-personal recognition respect on Darwall's account: to respect another is to either recognize and acknowledge the other person as (a) an authoritative member of the moral community whose demands generate moral obligations period or (b) as the particular individual-a self-originating source of valid claims-whose claims-based demands generate bipolar obligations that we have to her.

Since our focus is on bipolar obligations that we have to particular others, let's consider here again my obligation not to step on your foot. According to Darwall, I must refrain from stepping on your foot, because you have the individual authority to demand this of me. And it is only in recognizing and acknowledging your secondpersonal authority that I act for the right kind of reasons. For while I might actually do what I am said to owe to you - namely not to step on your foot-I could on Darwall's account still very much fail to grasp that it is within your individual authority to demand this of me, and consequently fail to acknowledge you as the source of my obligation. I might not actually step on your foot after all, simply because I take this to be my moral duty that I have independently of your valid claim against, or your standing or individual authority to demand anything of me. I would merely treat you as the target or "occasion" of my obligation that I have independently of any of your valid claims against me and thus fail to regard you as the separate "self-originating source" who has the individual authority to demand certain treatment of me:

\footnotetext{
${ }^{21}$ Darwall traces these reactive attitudes, personal- and impersonal alike, back to P.F. Strawson. See Strawson (1962: 84-85).
} 
"When I step on your feet unbidden, I fail to respect and so violate this authority you have as an individual person and so violate and fail to respect you. And in doing so, moreover, I fail to appreciate a reason not to step on your feet that is additional to the fact that I am causing avoidable harm, namely, that it violates your right, that is, on the current analysis, your legitimate demand of me as an individual person" (Darwall 2013a: 67)

On Darwall's account, then, I must conceive of my obligation to you as having its reason-generating source in the claim-based demand that you have the standing or individual authority to make, which is another way of saying that I must treat you with what I have identified as bipolar recognition respect. ${ }^{22}$

\subsection{Bipolar Obligations and Representative Authority}

Eventually, however, Darwall suggests that what ultimately underlies our bipolar obligations to particular others is the representative authority of the moral community. That is, Darwall holds that bipolar obligations always already "entail moral obligation period" and, hence that individual authority must also always already entail representative authority:

"If $\mathrm{X}$ is under obligation to $\mathrm{Y}$ to do $\mathrm{A}$, then $\mathrm{X}$ is, other things being equal at least, under a moral obligation period to do A. Actions that wrong someone (violate a bipolar obligation) are also wrong period, all else being equal, at least. If this is right, it follows that individual authority that is involved in bipolar obligations cannot exist without the representative authority that is involved in moral obligations period" (Darwall 2013a: 24).

Darwall's argument for this entailment claim is as follows: when it comes to morality, it is simply not the business of particular individuals like you and me to determine one another's obligation, even if the respective obligations are ones that are owed to you and me respectively.

To illustrate this point, Darwall gets us to think about the activity of blaming from the standpoint of the victim. Suppose I really violate my obligation to you and do in fact step on your foot without adequate excuse. When you blame me as a result of it - and in doing so implicitly address a moral demand to me that I ought to have acted otherwise-you don't just "vent or spout off," but rather intend to point out to me that I have done something blameworthy for which I should be held accountable. That is to say, your blame intends to draw me in an exchange and "comes with an implicit RSVP" which calls for acknowledgment on your behalf (Darwall 2006: 145).

\footnotetext{
22 That Darwall himself is committed to this intimate connection between bipolar obligations and recognition respect becomes clear when he notes "since duties owed to others are what they can legitimately claim deriving from their authority as 'self-originating sources of valid claims', in Rawls's phrase, failures to discharge them are failures to respect.” Darwall (2013b: 268).
} 


\subsubsection{Pufendorf's Point and Motivational Constraints}

In order for me to accept and acknowledge your blame, however, and feel guilty in return, I must, as it were, accept your blame and its implicit demand that I ought to have acted otherwise as being warranted (Darwall 2006: 28, 2013a: 139). For, I won't accept your blame as being justified just because 'you said so'. Instead, I will only accept your blame and feel guilty in return once I realize that the relevant demand implicit in your blame is one that could be made of me not just by you-the victim of my wrongdoing - but in fact by anyone, including myself, and hence by any representative member of the moral community. That is, I must realize that in wronging you, I have done something wrong, or wrong, period. Here is Darwall:

"[I] cannot adequately recognize [my] personal responsibility for injuring and thereby wronging [you] without also accepting that [my] actions were wrong period. And [I] cannot do that, unless [I] can believe this wrongdoing excusable, without blaming [myself], that is, by explicitly making a demand of [myself] that [I] see to be warranted from an impartial third-party perspective and accepting [my] own culpability. And this presupposes representative authority. It follows that the individual authority [you] have to object to [my conduct], cannot exist unless there is also a representative authority that everyone shares along with [you], including third parties and [myself], to hold [me] accountable through directive impersonal reactive attitudes like moral blame" (Darwall 2013a: 39. My interpolations. Emphasis added)

This is essentially what Darwall dubs Pufendorf's point, ${ }^{23}$ the thought that in genuinely obligating others and holding them accountable we must presuppose that they can blame and hold themselves accountable for the very same reason, and thus from a perspective that they and we share. Given that Darwall understands the relevant perspective to be the impartially disciplined perspective of the moral community and not simply that of two individuals being normatively implicated with each otherlike you and I-Pufendorf's Point comes in here to illustrate that "when [you] blame [me], [you simply] add [your] voice to or second, as it were, a demand that [you] must presuppose is made of everyone by the moral community or representative persons as such." Consequently, in blaming someone, according to Darwall, "whether someone else or ourselves, we implicitly address a demand, not at our own individual discretion, but as a representative person, on behalf of the moral community" (Darwall 2013a: 37. Emphasis added).

\footnotetext{
23 “Pufendorf's Point holds that genuine obligation can result only from an address that presupposes an addressee's second-personal competence. To intelligible hold someone responsible, we must assume that she can hold herself responsible in her own reasoning and thought." Darwall (2006: 23, 112).
} 


\section{Whence Bipolar Recognition Respect?}

If we grant Darwall's reading of Pufendorf's point it ultimately invites the following problem: how can we properly recognize particular others and their individual authority to make discretionary demands if our obligations to them are ultimately grounded in the shared representative authority of the moral community, and hence in non-discretionary demands? How can we make particular others "the proper object of our ethical concern" and treat them with bipolar recognition respect if all that fundamentally matters is to act in accordance with non-directed or monopolar moral requirements, or those we have "period?"

After all, Darwall and I are agreed that in demanding that I take my foot off of yours, I ought to acknowledge you as possessing the standing to make the relevant demand of me, or, alternatively, as the reason-giving source of my obligation that I have to you; I ought to treat you with bipolar recognition respect. Otherwise I would 'look through' or 'beyond' you, and in doing so wrong you by disregarding your valid claim against me, even if I was doing 'the right thing'. In acting merely from a non-discretionary "moral obligation, period," I would act for the wrong kind of reasons. While doing so might very well enable me to recognize you as the target of my obligation, it prevents me from recognizing and acknowledging you as the source of it. $^{24}$

\subsection{Resolving the Problem: A First Attempt}

Darwall might contest that my objection loses its footing once we realize that the mere claim that bipolar obligations always already entail moral obligations period does by no means commit him to the claim that bipolar obligations are ultimately grounded in moral obligations, period, if what we mean by grounded here is something like reducible to. The entailment relation that Darwall invokes does not yet amount to any reduction of individual authority to, and hence make it indistinguishable from, representative authority. All that the entailment relation explicates, according to Darwall, is a conceptual claim about bipolar obligations-whenever we make use of the concept of a bipolar obligation, we cannot do so without also invoking the concept of moral obligation period (Darwall (2013a: 24). That is simply to say that "individual authority cannot exist by itself" (Darwall 2013a: 27).

A little comparison might help to illustrate the point in question here. We can agree that the color-concept 'green' entails the concept 'color'. Hence, when we see a green colored object, we also always see a colored object, but not one that is also blue, red, or yellow at the same time. But by that, I take it, we do not mean to suggest that 'green' as a color concept is reducible to the concept 'color'. After all, green is not just a color, but instead a color of a distinctive kind. There are other colors, like blue, red, or yellow, and while all of them entail the concept 'color', none of them is just like the other. So, just because green, blue, red, and yellow all

${ }^{24}$ See Wallace (2007) for a related criticism. 
fall under the concept 'color', this does not mean that each of them merely signifies the concept 'color'; instead, they signify different color concepts. All that the entailment relation shows, then, is that some object that is green is also always a colored object, and not that it is only a colored object.

Therefore, Darwall might rightly respond to my worry that he is not claiming bipolar obligations to be simply reducible to, and hence indistinguishable, from moral obligations, period. Instead, all that the entailment claim shows is that in wronging someone we also always do something wrong, period. There should be nothing puzzling about that claim. Thus, we can still very much hold that bipolar obligations are distinct from moral obligations, period, on Darwall's view. And in fact, Darwall is adamant that we must indeed distinguish between the normativity of moral obligation, period, and the normativity of bipolar obligations in order to capture the important moral phenomenon of being obligated to someone in particular and its associated notion of wronging:

"I argue that bipolar moral obligations, that is, directed duties whose violation entails that the violating obligor has injured and, at least other things equal, wronged his obligee, also conceptually entail an authority to address claims and demands. However, the kind of authority distinctive of bipolar obligations is not representative authority but an individual authority that the individual obligee has to make claims and demands of an obligor who is obligated to him and to hold the obligor personally accountable" (Darwall 2013a: 185)

as well as

"Even so, a connection to the discretionary individual authorities we have discussed is surely part of the concepts of bipolar moral obligation and claim right. Failure to account for this distinctive second-personal aspect will miss an essential element" (Darwall 2013a: 35).

\subsubsection{The Problem of Normative Dependence}

A problem however still lingers. Properly read, Pufendorf's point does not appear to simply illustrate an entailment relation, but in fact an asymmetric dependence relation that holds between bipolar obligations and moral obligations, period. Darwall holds that your individual authority is ultimately derivative of, and hence secondary to, the representative authority of the moral community. ${ }^{25}$ That is, Darwall does not only hold that bipolar obligations simply entail moral obligations, period-that in wronging another one does something wrong period-but moreover, that the former depends on or presupposes the latter: "[A]ny special authority right holding obligees have can exist only if there is also an authority, representative authority, which they share with third parties, as well as with any obligor who might violate their rights" (Darwall 2013a: 30).

\footnotetext{
${ }^{25}$ See also Kadlac (2015) for invoking a similar line of objection to Darwall's account of bipolar obligation.
} 
It is one thing to claim that in stepping on your foot, I am in addition to acting contrary to your individual authority also acting contrary to the representative authority of the moral community, but yet another to claim that acting contrary to the former presupposes acting contrary to the latter. Ultimately, Darwall suggests that for your demand to give me reason to act, and hence to exert the relevant force or binding character, it needs to be normatively underwritten by the non-discretionary demand of the moral community.

While all of this does not necessarily conflict with the thought that any bipolar or relational obligation to $\varphi$ to B might very well be distinct from the merely monadic or non-relational obligation to $\varphi$, "period," it nevertheless appears to follow from Darwall's view that this bipolar obligation depends for its normative import on the existence of a monadic obligation, or a moral obligation, period. As a result, your individual authority is not normatively basic on Darwall's account. ${ }^{26}$

\subsubsection{The Morality-Plus View}

It begins to look as though the best you can do or have the standing to do is to merely "add [your] voice to or second, as it were, a demand that we must presuppose is made of everyone by the moral community or representative persons as such" (Darwall 2013a: 37). What I shall call the morality-plus view has the following implication ${ }^{27}$ : in going to visit Jane at the hospital, I am doing what Jane has the standing to demand of me, but only insofar as our mutual friends Peter and Stan also have the standing to justifiably demand the relevant action of me. More so, that Jane has the standing or individual authority to demand the relevant action of me in the first place depends on or presupposes, on Darwall's view, that Peter and Stan have the standing or representative authority to demand the relevant action of me, "period." That is, Darwall is not simply claiming that I'm always also under an 'obligation, period' whenever I'm under a bipolar obligation to Jane. On Darwall's view, I'm under a bipolar obligation to Jane if and only if I'm always already under an 'obligation, period'. For, what settles the fact of obligation is on Darwall's view ultimately the representative authority, and hence the authority that is as much Peter's and Stan's, as it is Jane's. But if the standing or authority to demand of me that I come visit Jane is available to anyone, including Peter and Stan, it is difficult to see how on Darwall's view Jane has special standing or "individual authority" to demand of me that I come visit her. After all, it is, as stated, far from clear what on Darwall's view normatively distinguishes Jane's standing from the standing of Peter and Stan to demand that I do what I owe to Jane. The distinction should amount to a clear division of normative labor between Jane's individual authority to make the

\footnotetext{
${ }^{26}$ Furthermore, it raises the question of what, if anything, gives you special standing or individual authority to demand of me not to step on your foot. If the justification for the demand is available to anyone in the moral community, it is difficult to see how that justification gives you any kind of special standing or 'individual authority' in the first place. After all, what relation do you bear to the demand that other members of the moral community do not?

27 For suggesting this term and helpful discussion about the following section, I'm indebted to Brendan de Kenessey.
} 
relevant demand of me, thereby settling the fact of obligation, and Peter's and Stan's representative authority to make the relevant demand of me on behalf of Jane. On Darwall's view, however, Peter's and Stan's standing to demand is not one they have on behalf of Jane. To the contrary, Peter's and Stan's standing is on a normative par with, and in fact normatively underlies, Jane's standing to demand, as a result of which there is no such clear distinction to be made. ${ }^{28}$ As a result, the thought that Jane is a "self-originating source of valid claims" who can exact bipolar recognition respect from me and obligate me to her in virtue of her valid claims seems to drop out of the picture, for Jane is nothing without Peter and Stan, or so it seems. ${ }^{29}$

Therefore, even if Darwall can resist any charges of simply reducing bipolar obligations to moral obligations period, he does not appear ready to do away with the problem stated in Sect. 3: How can we make particular others "the proper object of our ethical concern" and hence treat them with bipolar respect if all that fundamentally matters is to act in accordance with moral obligations, period? In merely being motivated to come visit Jane by thinking about what Peter, Stan, and Jane have the standing or authority to demand of me, I do not consider my obligation to be constitutively linked with only the valid claim and demand that Jane has against me, and hence not as an obligation that I owe specifically to Jane. As a result, I would fail to properly regard her as my friend who can, within the normative boundaries of our particular relationship, individually make demands of me, regardless of whatever anyone else might come to demand of me.

Another way to put all of this is to say that on Darwall's view, one possesses the second-personal standing of 'one among others', or of a representative member of the moral community who can never make any moral demands on behalf of herself, but only on behalf of the moral community, with the resulting obligation being one that others do not owe to someone in particular, but to the moral community, and hence "period."

\footnotetext{
${ }^{28}$ The point that Darwall is making here is not merely one about warrant; that Jane's claim needs to be such that it is open to anyone, including Peter and Stan, or even myself, to press the relevant claim against me on behalf of Jane. So much, I can agree on with Darwall. But Darwall's claim instead is that for Jane to have the standing to press a claim against or make a demand of me, Peter and Stan must have the standing to press a claim against me that I do what I owe to Jane in the first place. As a result, the normative current travels from representative authority to individual authority, and not the other way around; any bipolar or directed norms rest on, even if they don't reduce to, monopolar or non-directed norms. I'm grateful to two anonymous reviewers for pressing me to clarify the problem of normative dependence further here.

${ }^{29}$ To avoid possible confusion here, all of this is not to say, of course, that Jane can make the relevant demand of me only if, say, either Peter or Stan have actually addressed the relevant demand of me in the first place. That is, in calling me up and asking me to visit her, Jane does not need Peter or Stan to have done the same. Hence Jane very much functions as a separate source of valid claims when she actually calls me, thereby triggering me to do what I owe to her. But this is not the point in question here. As Darwall explicitly argues, he's not committed to the kind of voluntarist view, according to which Jane must actually address her demand to me in order for her to generate a bipolar obligation for me. What generates my bipolar obligation to Jane on Darwall's view is, to the contrary, simply Jane's claim or demand that she has the standing or individual authority to make of me. I'm grateful to an anonymous reviewer for asking me to clarify this here.
} 


\subsection{Resolving the Problem: A Second Attempt}

Darwall might object that this overlooks the fact that on his account there is indeed room for one to recognize and acknowledge another in accordance with the principle of bipolar recognition respect and hence avoid charges of acting for the wrong kind of reasons. Can we not recognize someone's discretionary authority to release, seek compensation, or hold others personally accountable? After all, Darwall might point out that any obligee has the individual authority others lack to hold the obligor personally accountable. Darwall can rightly stress that it is solely up to the victim to make certain rectificatory demands, such as the demand for an apology or compensation. Moreover, it is solely up to the obligee to consent to, or to enforce, insist on, or even to relieve another of, as it were, the relevant obligation that her obligor is under (Darwall 2013a: 30-31).

Think about the foot-stepping case again. ${ }^{30} \mathrm{We}$ 're both on the train to London and I am about to step on your foot. You see me eyeing your foot as a footstool to reach the luggage rack in the train. Now, it is reasonable to suppose that you can say, 'you can't do that-I demand that you not,' before I actually step on your foot. Here, it seems as though it is solely up to you to enforce or insist on my obligation not to step on your foot. And in following your demand not to step on your foot, it seems as though I treat you with bipolar recognition respect, that is, respect for you not only as the target of my obligation but at the same time as its very source. Alternatively, you might actually let me step on your foot in order to help me place my bag in the overhead locker, thereby relieving me of my obligation altogether. What is more, you might demand an apology or even forgive me for actually having stepped on your foot in order to place the luggage on the rack, thereby rendering any future blame inappropriate. No one else, it seems, has the individual authority to do just that. ${ }^{31}$

\subsubsection{The Post-obligation View}

Let's suppose that certain rectificatory obligations have their source exclusively in the individual authority of particular others and are hence robustly bipolar. ${ }^{32}$ At the same time, however, it is important to note that all of the relevant demands we are talking about here are in an important sense non-moral and come in post-obligation or ex post..$^{33}$ For, the relevant obligation to which you are holding me personally

\footnotetext{
30 I'm grateful to Stephen Darwall for helpful discussion on this section.

31 While a third party might not be able to ask for an apology or forgive me after I have stepped on your foot unbidden, he or she might, however, very well possess the standing to demand of me not to step your foot and thus the authority to enforce my obligation that I have to you.

32 It is not quite clear, however, whether or not Darwall really does eventually endorse this move, insofar as he holds that even a "personal reactive attitude, such as resentment, can be warranted, only if an impersonal reactive attitude [like blame] would be, other things equal, at least." Darwall (2013a: 69). My interpolation.

33 Post-obligation is here to be understood in terms of post-the-fact-of-obligation which needs to be distinguished from another post-the-time-for-compliance sense of post-obligation. As the previous elaborations should have shown, it would be a mistake to understand the notion of post-obligation merely in this latter temporal sense. After all, in understanding post-obligation in terms of post-the-time-for-com-
} 
accountable, or are insisting on and can actually relieve me of, is on Darwall's account one that is given to me prior, and, as it were, independently of any of your individual authority.

According to this narrow scope post-obligation view of bipolar obligations, it is within your exclusive power to hold me personally accountable for the obligation that I owe to you and in doing so for you to make legitimate post-obligation demands of me that are normatively based solely in your individual authority, e.g. to enforce the relevant obligation, to relieve me of my obligation, demand an apology, or ask for compensation.

\subsubsection{The Shortcomings of the Post-obligation View}

While the post-obligation view of bipolar obligations might indeed get around the problem of normative dependence that beset the morality-plus view, it does not seem ready to solve the problem stated in Sect. 3 either: How can we make particular others "the proper object of our ethical concern" and hence treat them with bipolar respect if all that fundamentally matters is to act in accordance with non-relational monadic moral requirements, or those we have period?

The puzzle about recognition respect and bipolar obligation emerged as a problem of an ex ante relation that holds between two individuals, that is, against the background of the claims underlying one's obligation yet to be undertaken to do $\varphi$ to another person, or what I call the fact of obligation. What the principle of bipolar recognition respect holds is that one must recognize and acknowledge another and his or her claims always as the reason-generating source of one's obligation to do $\varphi$ to the other, that is, as the reason for which one ought to do $\varphi$ to the other. Applied to the foot-stepping case, the principle of bipolar recognition respect requires of me to recognize and acknowledge you not only as someone who can claim or insist on any independently generated obligation and hold me personally accountable qua being the target or "occasion" of my obligation, but at the same time as the normative source of my obligation and hence as someone who has the standing to demand of me that I not step on your foot. But this is precisely what the post-obligation view is incapable of accommodating, for it is normatively inert with regard to the fact of obligation, and hence my initial obligation not to step on your foot. It follows that the post-obligation view cannot account for the principle of bipolar recognition respect, a principle that calls for the ex ante recognition of another person's valid claim. As such, it fares no better than the morality-plus view.

This is in no way to suggest that being obligated to another to, say, apologize-is in any way morally irrelevant. After all, this might help to illustrate how you have had a particular stake in my action. Thus, I agree with Darwall that to capture this in

Footnote 33 (continued)

pliance, we could not make sense of the idea that you possess the individual authority to insist on or enforce an obligation that I am under; recall the foot-stepping case again-before it is time for me to actually comply with the obligation you can say to me 'you can't do that-I demand that you not'. 
distinctively bipolar terms is of utmost importance if we want to give significance to such notions as wronging and victimhood (Darwall 2013a: 35).

\section{The Puzzle of Apology and a Relational Alternative}

Eventually, it turns out that Darwall's second-personal proposal will have difficulties to properly explain even these alleged ex post bipolar obligations. For, what Darwall misses in his analysis of ex post bipolar obligations, like the obligation to apologize, is that any such obligation presupposes the violation of a genuine ex ante bipolar obligation.

Let's think about the following in order to substantiate my claim here. When I step on your foot unbidden and without adequate excuse, you are in a position to demand an apology of me. In doing so, you point out to me that what I've done is not merely something that compels you to complain, but in fact something that warrants your blame and that I should feel guilty for in return. Your demand for an apology, however, asks for something more. It asks of me that I realize that what I did was not only "wrong period," but a wronging of you, as a result of which I should not only feel guilty, but guilty to you. For it is only in realizing that and acknowledging that what I have done amounts to an unexcused violation of your valid claim against me that you will accept my apology as sincere. In turn, this suggests that in apologizing to you, and doing so sincerely, I do not merely need to acknowledge that I have violated a moral obligation period, but rather a bipolar obligation that $\mathrm{I}$ had in virtue of your valid ex ante claim against me.

Doing so, however, becomes puzzling on Darwall's view, because the relevant ex ante claim underlying my initial obligation is on his second-personal account always ultimately grounded in the representative authority of the moral community and not in the individual authority of the person to whom I am obligated-you. For, what settles the fact of obligation on Darwall's second-personal account is the claim-based demand of the moral community, never that of the particular individual in question. Consequently, even Darwall's theory, which seeks to improve upon the purely non-directed models of morality by separating monopolar from bipolar obligations, fails to offer us with a more adequate theory of "what we owe to each" that is able to properly account for bipolar recognition respect.

\subsection{The Bipolar Standpoint}

What, then, does it take to offer a sincere apology to another? In one sense, I have already adumbrated an answer to that question; it takes acknowledgement of the fact that what one did to another was to disregard the valid ex ante claim or demand of the other. This, however, presupposes the uptake of a different moral standpoint from the all-, and in some sense over-, inclusive second-person standpoint that Darwall identifies. The relevant standpoint that a sincere apology presupposes is best characterized as holding exclusively between you and I, with "the rest of the world 
[...], at least to a certain extent, closed out" (Thompson 2004: 334). Let's call this the bipolar standpoint.

Deliberating from the bipolar standpoint, my obligation to you not to step on your foot presents itself as being constitutively linked with your valid $e x$ ante claim against me. That is, on a bipolar view of morality, your individual authority to demand certain treatment of me is normatively basic and does not depend on any representative authority that you share with any fellow train passengers. Understood in this way, your moral standing, or dignity, is not merely a standing as 'one among others', but fundamentally a standing 'for oneself'. You, as it were, possess the bipolar standing of an equally authoritative source of valid claims who can make (and be made) demands of (by) others on behalf of oneself, and who is owed (and owes) corresponding treatment by (to) another. It is in acting from an obligation that has its normative source in your bipolar standing that I act from the right kind of reasons and relate to you with bipolar recognition respect.

Adopting the bipolar standpoint as the relevant moral standpoint potentially presents a radical shift in moral theorizing and making good on it will require further substantive argumentation. For in adopting the bipolar standpoint we no longer separate monopolar obligations that are owed to no one in particular from bipolar obligations that are owed to particular individuals. Quite to the contrary, each and every obligation ranging over the interpersonal moral sphere now turns out to be a bipolar obligation that is owed to, and incurred because of, a particular individual..$^{34}$ On the resulting view, I'm not just under an obligation, "period," to separate my trash; I, in fact, owe it to each of my fellow citizens to do so. If the arguments of the paper carry some weight, however, it will become imperative to take this bipolar proposal serious as an alternative contender for a plausible theory of "what we owe to each other."

One might immediately worry that in locating the normative source of our obligations solely in the individual authority of another, and without any appeal to the non-discretionary representative authority underlying it, others seem to simply impose their will on ours or command us to do certain things to them. On this view, one might think, we would come under obligations to others simply 'because they say so'. And this can't be right. But the bipolar view doesn't need to have this consequence.

Recall Pufendorf's Point: if I ask you why I ought to obey your demand not to step on your foot, it does not suffice for you to simply say, 'Because I said so', if all that you mean by that is just that you can command me and hence impose an obligation on me by communicating the very intention to do so. You, after all, are not my general. Rather, you must tell me 'Because it's wrong to do otherwise', and in doing so point towards or trigger a reason that warrants your demand, thereby abstaining

\footnotetext{
${ }^{34}$ Importantly, this is not to say that we can no longer speak of something being 'wrong, period'. It might, after all, be 'wrong, period' to step on your foot. This might be because the fact that I'm violating a bipolar obligation to you always provides sufficient justification for the moral community to demand that I not do so. Instead of individual claims normatively depending on representative claims, however, any representative or third-party claims normatively depend on, and function as trustee-claims of, the primary claims of individuals like yourself.
} 
from self-conceit and moral arrogance that manifest itself in "the presumption that one has the kind of worth or dignity oneself" to assert something having "objective normative significance because it is what one wills subjectively" (Darwall 2006: 134-135).

I grant, and in fact accept, Pufendorf's Point: in being obligated by the claims and demands of another I must be able to make the claim or demand of myself for the very same reason the other person makes it of me. That is, you must point to, as it were, a warrant and one, moreover, that I cannot reasonably reject. But is your only option to warrant your demand of me to appeal to the representative authority or standing that the moral community has to make the relevant demand of me? After all, Pufendorf's point merely holds that the person obligated (obligor) and the person obligating (obligee) must share a deliberative perspective-it only claims that you and I must share the reasons that warrant your demand of me. Nothing in Pufendorf's point itself says that this shared perspective must be the all-inclusive perspective of the moral community.

When Jane expects of me to come visit her, she expects bipolar competence of me- to take up the perspective that is uniquely tied to our friendship and to grasp the underlying reason for my obligation to her. Jane does not expect of me to take up a perspective that we share with the rest of our friends. Doing so would, in fact, be a mistake on my part. After all, what I owe to Jane, and what Jane is in a position to demand or expect of me, is in an important sense no one else's business. ${ }^{35}$ At the same time, Jane can't demand just anything of me. While it might be convenient for her to have breakfast brought to her bedside every morning, it hardly follows that she has a valid claim against me that I do so. She has the standing to claim against or demand of me only what I, as her friend, can come to acknowledge as obligating me from our shared deliberative perspective-the bipolar standpoint.

Let me be clear. Darwall is right in thinking that we must adhere to certain nonpersonal standards in order to validate our claims. But we must be careful to distinguish between two senses of non-personal here: one in terms of 'non-subjective' (s) and one in terms of 'non-relational' (r). While we clearly must adhere to nonpersonal (s) standards, it is not clear that these cannot be inherently bipolar (r). That is, while we cannot validate our claims simply in virtue of, say, subjective preferences, e.g. Jane's preference to have breakfast brought to her bedside, we can, as I have suggested, do so relationally, that is, within the context of a bipolar two-person relationship. Accordingly, my hunch is that Jane's claim to be visited in the hospital by me is validated by a bipolar reason that the two of us share, that is, a reason that is exclusive to and derivative of our relationship, and hence a reason for and of just the two of us, not anyone else.

\footnotetext{
35 As Radzik (2011) points out, Jane and I might, in virtue of our friendship, even have a claim against third parties that they not sanction the wrong I have done to Jane as a means to protecting the special value of our relationship: "The claim amounts to a demand that the third party respect the integrity of a special relationship that is crucial to the parties' ability to develop their own agency and pursue their own conception of the good." Radzik (2011: 594). This is another way of saying that the perspective from which we determine what we owe to each other as friends is exclusively Jane's and mine.
} 
Bipolar reasons do not concern what (a) persons in general or (b) each and every person might have a claim to, but what a particular person-Jane-has a claim to in a given situation and within the context of a particular relationship, i.e. her friendship with me. When it comes to settling the fact of obligation, then, it is the bipolar reason that I exclusively share with Jane that does so, and not any all-inclusive second-personal reason Jane and I also happen to share with Peter or Stan. To fail to realize this, amounts to a failure to grasp the importance of particular individuals and the relationships we share with them, on the one hand, and the possibility of conflicts that can emerge in virtue of competing obligations, on the other hand. Regarding the latter, consider the following: Jane might well have a valid claim against me that I come visit her, while Stan also has a valid claim against me that I help him after having been injured in a car accident. As a result, I'm under an obligation to Jane and Stan respectively, but can only comply with one of these obligations. Hence, these two claims conflict and present me with a dilemma. But they do conflict with each other and present me with a dilemma only, because both claims are initially warranted. What plausibly warrants them are the bipolar standpoints and the reasons emerging from them that I share with Jane and Stan, respectively, and not, importantly, any reason that derives from either a set of impartial general moral principles or the all-encompassing second-personal standpoint that I at the same time share with both Jane and Stan. All of this is to suggest that claims and demands of particular individuals can be warranted by reasons that are non-personal (s), but, importantly, relational or bipolar.

While working all this out in much more detail is certainly necessary in order to make good on the promise of a genuinely bipolar theory of "what we owe to each other," there is then no reason why we should think that, in principle, the bipolar standpoint cannot also adhere to Pufendorf's point, which prevents its participants from simply imposing their wills on each other. That is, I suspect, the flaw in Darwall's argument- to fail to see that the basis for the claim and subsequent standing to demand could in principle be shared between two individuals without being shared by all moral agents as such.

Acknowledgements For helpful feedback and comments on earlier drafts I would like to thank Han van Wietmarschen, Stephen Darwall, Douglas Lavin, Andrew Knox, Brendan de Kenessey, Senthuran Bhuvanendra, two anonymous reviewers for the Journal of Ethics, and audiences at University College London and the University of Bonn. I'm deeply grateful in particular to Han van Wietmarschen and Stephen Darwall for all their support.

Open Access This article is distributed under the terms of the Creative Commons Attribution 4.0 International License (http://creativecommons.org/licenses/by/4.0/), which permits unrestricted use, distribution, and reproduction in any medium, provided you give appropriate credit to the original author(s) and the source, provide a link to the Creative Commons license, and indicate if changes were made.

\section{References}

Brandt, Richard. 1959. Ethical Theory. Englewood Cliffs, NJ: Prentice-Hall.

Cornell, Nicholas. 2015. Wrongs, Rights, and Third Parties. Philosophy \& Public Affairs 43(2): 109-143. 
Darwall, Stephen. 2006. The Second-Person Standpoint: Morality, Respect, and Accountability. Cambridge: Harvard University Press.

Darwall, Stephen. 2013a. Morality, Authority, and Law: Essays in Second-Personal Ethics I. Oxford: Oxford University Press.

Darwall, Stephen. 2013b. Honor, History, and Relationship: Essays in Second-Personal Ethics II. Oxford: Oxford University Press.

Feinberg, Joel. 1970. The Nature and Value of Rights. The Journal of Value Inquiry 4(4): 243-260.

Foot, Philippa. 1994. Rationality and Virtue. In Norms, Values, and Society, ed. H. Pauer-Studer. Amsterdam: Kluwer.

Gilbert, Margret. 2004. Scanlon on Promissory Obligation: The Problem of Promisee's Rights. The Journal of Philosophy 101(2): 83-109.

Hart, H.L.A. 1955. Are there any Natural Rights? Philosophical Review 64(2): 175-191.

Hohfeld, Wesley. 1923. Fundamental Legal Conceptions, ed. Walter Wheeler Cook. New Haven, CT: Yale University Press.

Hooker, Brad. 2000. Ideal Code, Real World: A Rule-Consequentialist Theory of Morality. Oxford: Oxford University Press.

Kadlac, Adam. 2015. Does It Matter Whether We Do Wrong? Philosophical Studies 172(9): 2279-2298.

Kamm, F.M. 2007. Intricate Ethics: Rights, Responsibilities, and Permissible Harm. New York: Oxford University Press.

Kumar, Rahul. 2003. Who can be Wronged? Philosophy \& Public Affairs 31(2): 99-118.

Lavin, Douglas. 2014. Other Wills: The Second-Person in Ethics. Philosophical Explorations: An International Journal for the Philosophy of Mind and Action 17(3): 279-288.

Lyons, David. 1970. The Correlativity of Rights and Duties. Nous 4(1): 45-55.

May, Simon Cabulea. 2015. Directed Duties. Philosophy Compass 10(8): 523-532.

O’Neill, Onora. 1989. Constructions of Reason. Cambridge: Cambridge University Press.

Radzik, Linda. 2011. On Minding Your Own Business: Differentiating Accountability Relations within the Moral Community. Social Theory and Practice 37(4): 574-598.

Railton, Peter. 1984. Alienation, Consequentialism, and the Demands of Morality. Philosophy\&Public Affairs 13 (2):134-171

Raz, Jopeph. 1986. The Morality of Freedom. Oxford: Clarendon Press.

Scanlon, T.M. 1998. What We Owe to Each Other. Cambridge: Harvard University Press.

Scanlon, T.M. 2013. Reply to Leif Wenar. Journal of Moral Philosophy 10(4): 400-405

Smith, Michael. 1994. The Moral Problem. Malden, MA: Blackwell.

Sreenivasan, Gopal. 2010. Duties and Their Direction. Ethics 120(3): 465-494.

Stocker, Michael. 1976. The Schizophrenia of Modern Ethical Theories. The Journal of Philosophy 73(14): 453-466.

Strawson, P.F. ed. 1962. Freedom and Resentment. In Freedom and Resentment and Other Essays. New York: Routledge.

Thompson, Michael. 2004. What is it to Wrong Someone? A Puzzle about Justice. In Reason and Value: Themes from the Moral Philosophy of Joseph Raz, ed. R. Jay Walllace, Samuel Scheffler, Philip Pettit, and Michael Smith, 333-384. Oxford: Clarendon Press.

Thomson, Judith Jarvis. 1990. The Realm of Rights. Cambridge, MA: Harvard University Press.

Wallace, R. Jay. 2007. Reasons, Relations, and Commands: Reflections on Darwall. Ethics 188(1): 24-36.

Wallace, R. Jay. 2019. The Moral Nexus. Princeton, NJ: Princeton University Press.

Weinrib, Ernest. 1995. The Idea of Private Law. Oxford: Oxford University Press.

Wenar, Leif. 2013. Rights and What We Owe to Each Other. Journal of Moral Philosophy 10(4): 375-399.

Zylberman, Ariel. 2017. Two Second-Personal Conceptions of the Dignity of Persons. European Journal of Philosophy 25(4): 921-943.

Publisher's Note Springer Nature remains neutral with regard to jurisdictional claims in published maps and institutional affiliations. 